\title{
Morphophysiological characteristics of pollen grains produced by bisexual inflorescences of silver birch (Betula pendula Roth.)
}

\author{
Lukasz Grewling (iD · Lukasz Piosik • Piotr Szkudlarz
}

Received: 19 May 2020/ Accepted: 3 November 2020/Published online: 21 November 2020

(C) The Author(s) 2020

Silver birch (Betula pendula Roth., family Betulaceae, order Fagales) produces pollen grains in pendulous male (staminate) inflorescences (catkins), that are formed 1 year before flowering. Birch catkins elongate during summer months until they reach the dormancy phase (winter rest). At this stage catkins are short, dense and contain microspores. In the next season, after breaking the dormancy, the development of pollen grains is renewed (Dahl and Strandhede 1996; Holm 1994). A few weeks later, in Poland,

Electronic supplementary material The online version of this article (https://doi.org/10.1007/s10453-020-09678-0) contains supplementary material, which is available to authorized users.

Ł. Grewling $(\bowtie)$

Laboratory of Aerobiology, Department of Systematic and Environmental Botany, Faculty of Biology, Adam Mickiewicz University in Poznań, Uniwersytetu

Poznańskiego 6, 61-614 Poznan, Poland

e-mail: grewling@amu.edu.pl

Ł. Piosik

Department of General Biology, Faculty of Biology, Adam Mickiewicz University in Poznań, Uniwersytetu Poznańskiego 6, 61-614 Poznan, Poland

P. Szkudlarz

Department of Systematic and Environmental Botany, Faculty of Biology, Adam Mickiewicz University in Poznań, Uniwersytetu Poznańskiego 6, 61-614 Poznan, Poland usually in April and May, mature pollen grains are released from long fully developed catkins (Grewling et al. 2012). In contrast, female (pistillate) inflorescences overwinter as primordia and emerge just before pollination after breaking off the short shoot buds in which they developed (Holm 1994). Female flowers are greenish, erect and much thinner and shorter than the male catkins. As a rule, the inflorescences of silver birch (both male and female) are therefore unisexual, located separately on the tree (Hynynen et al. 2010).

During the field surveys in 2019 and 2020, we observed bisexual catkins with female flowers in its basal part and male flowers in the distal region in two individuals of Betula pendula growing in Poznan (Western Poland). Bisexual catkins have been previously reported in B. pendula (Kosmin 1982) and the morphological structure of bisexual catkins of $B$. pubescens has been thoroughly described by Tolstopyatenko (1974). The information about pollen grains produced by these catkins are however very scarce and limited only to pollen grain diameter and germination data (Tolstopyatenko 1974, Makhnev and Korobchenko 1976). In this short communication, we present the morphophysiological characteristics of pollen grains produced by bisexual catkins of $B$. pendula with particular emphasis on such features as: vitality, germinability and allergenicity. The possible evolutionary significance of this phenomenon, with respect to projected shifts in silver birch distribution 
due to climate change (Dyderski et al. 2017), is also discussed.

Bisexual inflorescences of silver birch were found in Poznań on two fully flowering trees (on 8 April 2019 and 13 April 2020, respectively) at two different locations. The first stand is dominated by four storey buildings, neglected open space and local streets $\left(52^{\circ}\right.$ $26^{\prime} 40^{\prime \prime} \mathrm{N}, 16^{\circ} 56^{\prime} 48^{\prime \prime} \mathrm{E}$ ), while the second one is located near the lake and surrounded by well-kept green areas $\left(52^{\circ} 27^{\prime} 35^{\prime \prime} \mathrm{N}, 16^{\circ} 49^{\prime} 47^{\prime \prime} \mathrm{E}\right)$. The inflorescences were at various stages of development, i.e., from dwarf approximately $1 \mathrm{~cm}$ long to fully developed pendulous catkins (Fig. 1). They were found together with normally developed staminate and pistillate catkins. Bisexual inflorescences consisted of two separate zones, i.e., female flowers were in the basal part of the inflorescence ("female zone"), while male flowers were in its distal part ("male zone"), resembling the situation of previously described bisexual catkins of $B$. pendula (Kosmin 1982). In a particular zone, both pistils and anthers were normally developed. However, in the transition zone (between female and male zones) the pistils and anthers were underdeveloped and distinctly smaller (Fig. 1S).
The mean diameter of pollen grains collected from catkins (50 pollen grains were measured) was approximately $21.5 \mu \mathrm{m}$ (both in the polar and equatorial axes) (Fig. 2S). These results concur with the size of pollen grains released by normally developed inflorescences. For example, Piotrowska (2008) documented that the dimensions of silver birch pollen grains were 21.3 (equatorial axis) $\times 18.2$ (polar axis) $\mu \mathrm{m}$. Makhnev and Korobchenko (1976) who investigated bisexual inflorescences in Betula pubescens ssp. tortuosa, found no differences in the pollen grain diameter produced by flowers from various zones of bisexual catkins. The microstructure of the exine of pollen grains (taking into account the size and shape of fine granules and verrucate pattern) collected from bisexual catkins in Poznań does not differ from the pollen grains released by normally developed male catkins (another tree from the same location) (Fig. 3S). With the exception of typical triporate pollen grains, tetra- and pentaporate pollen grains were also observed (Fig. 2). These abnormal deformed pollen grains, however, were not common - on 250 counted pollen grains we noticed 15 tetraporate $(6.0 \%)$ and 2 pentaporate pollen grains $(0.8 \%)$. The rare occurrence of tetra- and pentaporate
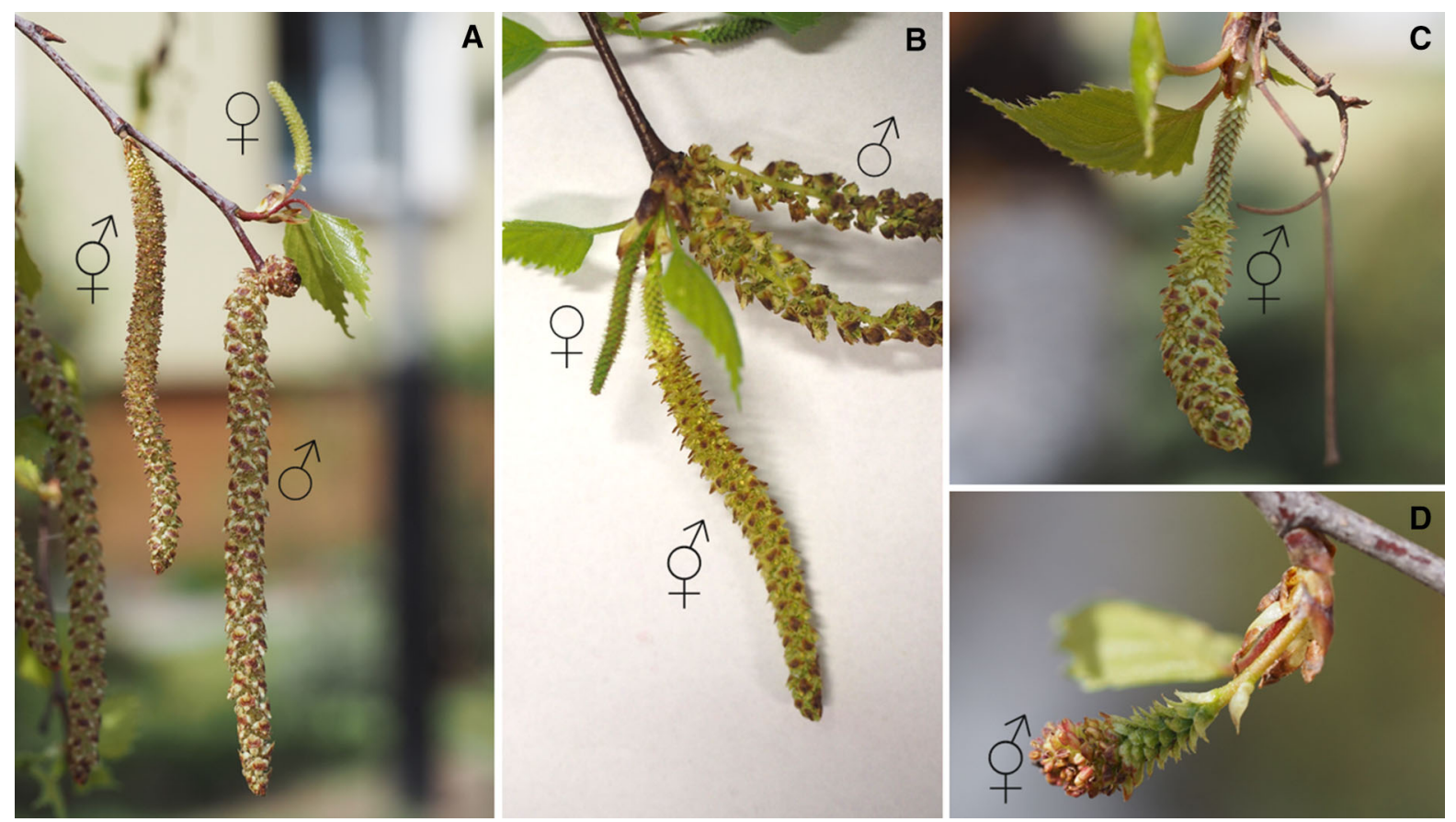

Fig. 1 Bisexual inflorescences of silver birch during different developmental stages: a comparison of unisexual and bisexual catkins, b fully developed catkins releasing pollen, c pre-flowering stage, $\mathbf{d}$ dwarfy catkins 

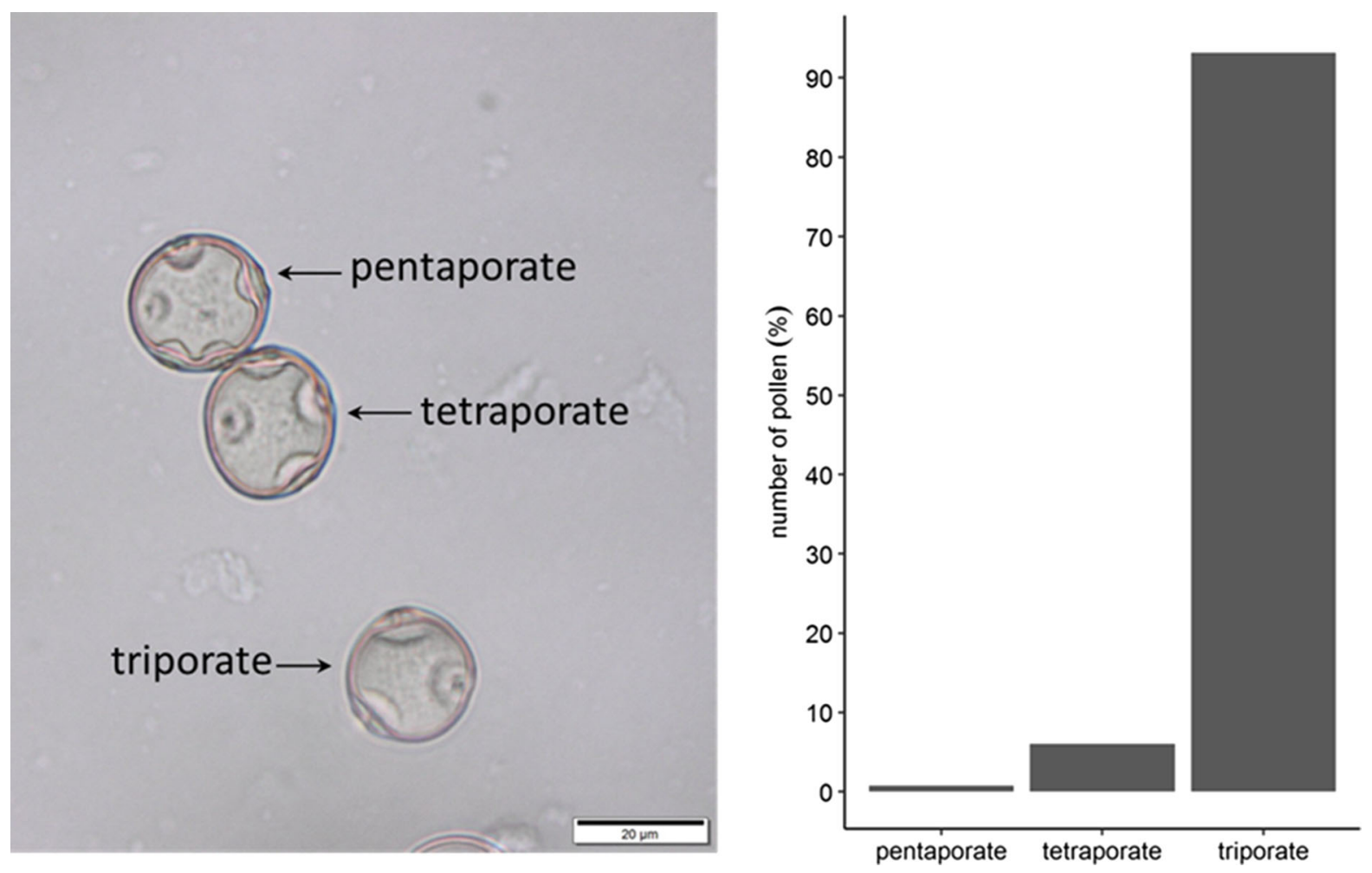

Fig. 2 Tetra- and pentaporate birch pollen grains released from bisexual catkins. Proportion of tri-, tetra-, and pentaporate pollen grains in the sample $(\mathrm{n}=250)$

pollen grains in Betula genus has been previously reported by Karlsdóttir et al. (2008). They observed deformed (di-, tetra- and pentaporate) pollen grains in Betula nana, Betula pubescens and their natural hybrids in Iceland. Pollen with four pores was found in $2.3 \%$ of $B$. nana pollen examined, $0.7 \%$ of $B$. pubescens pollen, and $10.8 \%$ in the hybrid pollen. The presence of abnormally developed pollen grains was not reported from bisexual catkins of B. pubescens ssp. tortuosa (Makhnev and Korobchenko 1976).

Our observations have shown that the vast majority of collected bicellular pollen grains have been fully developed. Generative nuclei, usually localized in the central part of pollen grains, were clearly visible (Fig. 3a) in pollen grains stained with $4^{\prime}, 6$-diamidino2-phenylindole (DAPI-10 $\mu \mathrm{g} / \mathrm{ml} \mathrm{H}_{2} 0$ ) or acetocarmine (1\% carmine in $45 \%$ glacial acetic acid) (Fig. 3a, b). The dense cytoplasm of most of the pollen grains analyzed (Fig. 3b) was intensively stained with acetocarmine. Normal pollen tube formation was also observed after a 24-h incubation in $10 \%$ sucrose solution (with $\mathrm{MgSO}_{4}, \mathrm{Ca}\left(\mathrm{NO}_{3}\right)_{2}$, and $\mathrm{H}_{3} \mathrm{BO}$ )
(Fig. 3c) concurring with the observations of Tolstopyatenko (1974). In addition, pollen allergenicity (expressed as the amount of the major birch pollen allergen, Bet v 1, released from pollen) was calculated by immunoeznytamic assay according to the method described in Buters et al. (2012). The allegenicity of pollen released from bisexual catkins reached $1.80 \mathrm{pg}$ Bet $\mathrm{v} 1$ /pollen and was only slightly lower from birch pollen allergenicity recorded from other locations in Europe (from 2.3 to $3.9 \mathrm{pg}$ Bet v 1/pollen) (Buters et al. 2012). Thus, pollen grains of bisexual inflorescences may potentially induce allergy reactions in sensitized individuals.

Tolstopyatenko (1974) noted that bisexual catkins origin from female buds and begin to emerge in the summer a year before pollination. In winter, these inflorescences look like male inflorescences, although a certain part of the catkins is still inside the bud. In spring, the part hidden in the bud produces female flowers, resulting in a most common type of bisexual catkins, i.e., with female flowers in its basal part and male flowers in distal region (however other structural 

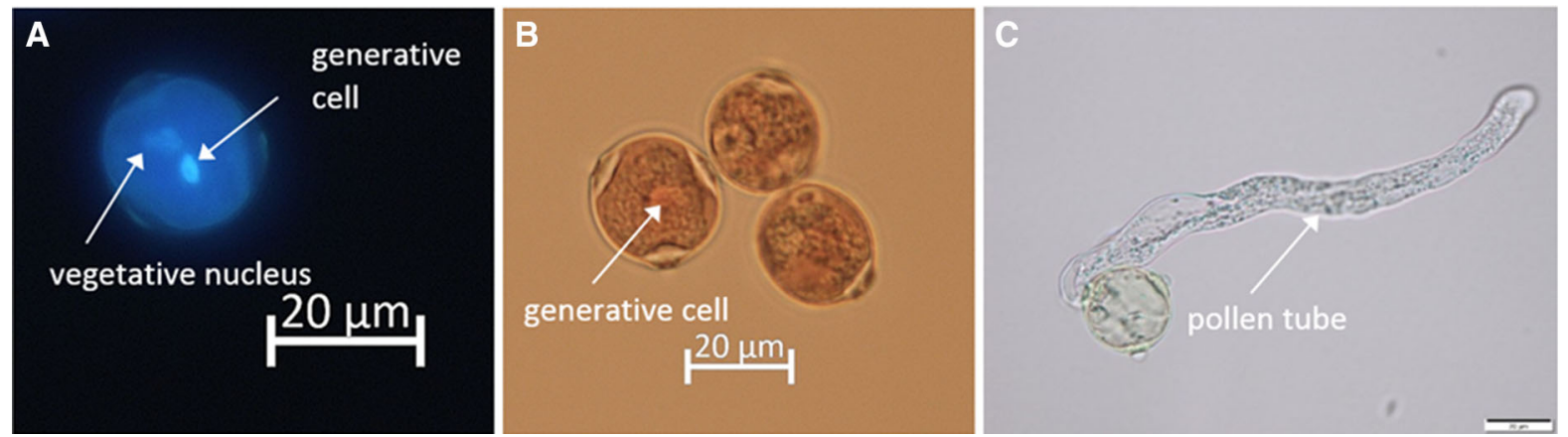

Fig. 3 Viability and germination of pollen grains: a bicellular pollen grain stained with DAPI, b pollen grains stained with acetocarmine, $\mathbf{c}$ pollen tube formation

variations of bisexual catkins were observed, too). Hypothetically, some environmental stressors, likely light or temperature, impacting on protruding catkins influence the expression of certain genes responsible for sex determination. The impact of stress factors on sex determination has already been observed in some plant species other than birch. For instance, it has been shown that damage stress (full defoliation or severe pruning) can change sex ratio in Acer pensylvanicum (Blake-Mahmud and Struwe 2020). In birches, it was revealed that BpDEF may function in sex-determination and, in particular, specify the identity of male inflorescence. This gene is additionally controlled by BpAP1 that affects the expression of many floweringrelated genes (Wang et al. 2019). So far, however, it is unknown whether BpAP1 or BpDEF can be activated or deactivated by any environmental stress factor, although Kosmin (1982) observed that birch trees that grow in good light conditions produce more female catkins than shaded trees.

Similarly, it is not known why certain female buds start developing so early, i.e., a year before the normal female buds. Most examples of catkin bisexuality in birch come from observations of trees growing in "atypical" conditions, e.g., at the margin of the distribution range, in greenhouses or from introduced species (Tolstopyatenko 1974, Makhnev and Korobchenko 1976). It again suggests that certain stressors can alter the normal pathway of bud development resulting in premature emergence of catkins from buds. In Poznań, bisexual catkins were noted on trees with good access to light or exposed to elevated temperatures (wide open spaces, tall buildings, proximity to roads). It should be emphasized, however, that both trees grow in close proximity to other birch trees on which no bisexual catkins were observed. It is also worth noting that bisexual catkins of silver birch have also been found in the natural population (Kosmin 1982). It has been suggested that the presence of bisexual catkins was related to the weak health of trees, as the trees with bisexual catkins were smaller and had a smaller trunk diameter than other trees in the population.

In Europe, the southern distribution range of $B$. pendula is limited by the amount of rainfall during summer (Atkinson 1992). In 2019, during extremely dry summer, the drought-related mortality of $B$. pendula was noted in Poznań (personal unpublished observations). There are projections suggesting that the distribution of silver birch in Central Europe will decrease due to climate warming (Dyderski et al. 2017). If the appearance of bisexual catkins is influenced by some "unusual" unfavorable environmental conditions, than at the margin of the current distribution range, e.g., southern Europe, such bisexual catkins should be more frequently observed. Similarly, the number of individuals of silver birch with bisexual catkins may also increase in Central Europe due to the recent aridification caused by climate change.

Funding Not applicable.

Availability of data and materials Birch catkins are stored at AMU Poznań, Poland. Available upon request.

\section{Compliance with ethical standards}

Conflict of interest Not applicable.

Open Access This article is licensed under a Creative Commons Attribution 4.0 International License, which 
permits use, sharing, adaptation, distribution and reproduction in any medium or format, as long as you give appropriate credit to the original author(s) and the source, provide a link to the Creative Commons licence, and indicate if changes were made. The images or other third party material in this article are included in the article's Creative Commons licence, unless indicated otherwise in a credit line to the material. If material is not included in the article's Creative Commons licence and your intended use is not permitted by statutory regulation or exceeds the permitted use, you will need to obtain permission directly from the copyright holder. To view a copy of this licence, visit http://creativecommons.org/licenses/by/4.0/.

\section{References}

Atkinson, M. D. (1992). Betula pendula Roth (B. verrrucosa Ehrh.) and B. pubescens Ehrh. Journal of Ecology, 80(4), 837-870.

Blake-Mahmud, J., \& Struwe, L. (2020). When the going gets tough, the tough turn female: injury and sex expression in a sex-changing tree. American Journal of Botany, 107(2), 339-349.

Buters, J. T. M., Thibaudon, M., Smith, M., Kennedy, R., Rantio-Lehtimäki, A., Albertini, R., et al. (2012). Release of Bet v 1 from birch pollen from 5 European countries. Results from the HIALINE study. Atmospheric Environment, 55, 496-505.

Dahl, A., \& Strandhede, S. O. (1996). Predicting the intensity of the birch pollen season. Aerobiologia, 12, 97-106.

Dyderski, M. K., Paź, S., Frelich, L. E., \& Jagodziński, A. M. (2017). How much does climate change threaten European forest tree species distribution? Global Change Biology, 24(3), 1150-1163.

Grewling, Ł., Jackowiak, B., Nowak, M., Uruska, A., \& Smith, M. (2012). Variations and trends of birch pollen seasons during 15 years (1996-2010) in relation to weather conditions in Poznań (western Poland). Grana, 51(4), 280-292.

Holm, S. O. (1994). Pollination density-effects on pollen germination and pollen tube growth in Betula pubescens Ehrh. in northern Sweden. New Phytologist, 126, 541-547.

Hynynen, J., Niemisto, P., Vihera-Aarnio, A., Brunner, A., Hein, S., \& Velling, P. (2010). Silviculture of birch (Betula pendula Roth and Betula pubescens Ehrh) in northern Europe. Forestry, 83(1), 103-119.

Karlsdóttir, L., Hallsdóttir, M., Thórsson, A Th, \& AnamthawatJónsson, K. (2008). Characteristics of pollen from natural triploid Betula hybrids. Grana, 47, 52-59.

Kosmin, A. B. (1982). Bisexual inflorescences in Betula pendula (Betulaceae) in natural environments. Botanicheskii Zhurnal, 67(9), 1248-1256.

Makhnev, A. K., \& Korobchenko, O. B. (1976). Anomalies of structure of reproductive organs of Betula tortuosa in alpine subpolar Urals. Botanicheskii Zhurnal, 61(8), 1160-1166.

Piotrowska, K. (2008). Pollen production in selected species of anemophilous plants. Acta Agrobotanica, 61(1), 41-52.

Tolstopyatenko, A. I. (1974). Bisexual inflorescences in Betula species. Botanicheskii Zhurnal, 59(12), 1834-1844.

Wang, S., Huang, H., Han, R., Chen, J., Jiang, J., Li, H., et al. (2019). BpAP1 directly regulates BpDEF to promote male inflorescence formation in Betula platyphylla x B.pendula. Tree Physiology, 39, 1046-1060. 